\title{
18 HYDROLYTIC POLYMERISATION OF IRON(III)
}

Potentiometric and other studies by a number of investigators have implicated a binuclear complex, $\left[\mathrm{Fe}_{2}(\mathrm{OH})_{2}\right]^{4+}$, as the predominant hydrolysis species in solutions of iron(III) even at pHs less than $2^{9-13}$. Continued hydrolysis of iron(III) solutions readily leads to the formation of various poorly characterised polymeric precipitates and, eventually, to the formation of the insoluble brown polymerisation product, iron(III) hydroxide $\left(K_{\mathrm{sp}}=10^{-38.7}, 25^{\circ}, 3 \mathrm{M} \mathrm{NaClO}_{4}{ }^{14}\right.$. Although this familiar brown colloid has usually been assumed to be amorphous and ill defined, hydrolysates that are of small particle size ( $<10 \mathrm{~nm}$ diameter) but of sufficient crystallinity to give X-ray powder patterns have been isolated recently ${ }^{15,16}$. The iron(III) oxide and iron(III) oxyhydroxide systems contain several crystalline phases: $\alpha-, \beta-, \gamma-\mathrm{Fe}_{2} \mathrm{O}_{3}, \mathrm{Fe}_{3} \mathrm{O}_{4}$, and $\alpha-, \beta-, \gamma-, \delta-\mathrm{FeOOH}$. Their structures and interconversions have been extensively studied $^{17,18}$.

Inclusion of chelating agents in hydrolysed iron(III) solutions has led to the isolation of stable dimeric complexes. The proposed dimeric unit ${ }^{19-21}$ of the chelatefree system, $\left[\mathrm{Fe}(\mathrm{OH})_{2} \mathrm{Fe}\right]^{4+}$, has been observed in the crystal structure of a dimeric species isolated from the iron(III)-picolinic-acid system ${ }^{22}$. Many dimers are analogous to that formed with HEDTA ( $\mathrm{N}^{\prime}$-(2-hydroxyethyl)ethylenediamine-N,N,N'triacetic acid), the crystal structure of which shows an almost linear $\left(165^{\circ}\right)$ oxobridged $\mathrm{Fe}-\mathrm{O}-\mathrm{Fe}$ structural unit linking the two subunits of the molecule together ${ }^{23}$.

Gel filtration and ultrafiltration of an iron(III) nitrate solution to which two moles of $\mathrm{OH}^{-} / \mathrm{Fe}$ had been added resulted in the isolation of a remarkably homogeneous polymer, of molecular weight 150000 , incorporating about 1200 iron atoms ${ }^{24,25}$. It appears spherical in the electron microscope with a diameter of $7 \mathrm{~nm}$. An iron(III)citrate polymer also appears spherical, $7 \mathrm{~nm}$ in diameter, with a molecular weight of $2.1 \times 10^{526,27}$. A polymer of molecular weight $0.65 \times 10^{5}$ has been isolated by alcohol-induced precipitation from iron(III)-fructose solutions ${ }^{28}$. 